\title{
EDITORIAL
}

\section{Scientists and sustainable development}

\begin{abstract}
"We are passersby in this world and are only temporary guardians holding in trust the environment for the use of not only ourselves but also for the future generations". These words of a Red Indian Chief uttered centuries ago is of such value to human kind, that it is still remembered today. However, mankind has not heeded these words in their quest for development. These words are of paramount importance to us Sri Lankans as we embark on programmes of development to change from a developing to a developed nation.
\end{abstract}

All developmental activities are undertaken with a view to change the existing situations for the betterment of the people. These activities however, must not be carried out at the expense of the future generations of the country. It is important that whatever developmental work undertaken by the present generation needs to be executed so as not to compromise the needs of the future generations, which is the basis for sustainable development.

The decision makers including the government, its advisers, experts and consultants, bureaucrats and technocrats have to realise that their decisions have long lasting effects both good and bad for the country. They also have to keep in mind that sustainable development of a country rests on three pillars - Environment, Society and Economy. The research scientists also must realise that their activities must have a focus on sustainable development of the country.

The importance of sustainable development in the country's planning process was identified more than a decade ago and gathered momentum in 2007 with an initiative taken by the Ministry of Environment and Natural Resources, which developed a National Strategy for Sustainable Development. Subsequently, an action plan was developed for the period 2008 - 2011. This was later updated into a 5 year action plan referred to as Caring for Environment 2009 - 2013. An extended action plan, referred to as the National Action Plan for Haritha (Green) Lanka Programme, was subsequently developed through an extensive consultative process including all key developmental ministries. It covered the period 2009 - 2016 with short term $(2009-2010)$, medium term (2009 - 2013) and long term (2009-2016) goals.

The government established a National Council for Sustainable Development (NCSD) under the chairmanship of the President, with the objective of 'producing an integrated policy and overseeing and guiding the implementation of the Haritha Lanka Programme to ensure the sustainability of social and economic development programmes'. More recently, the government adopted a new 'blue-green development strategy for the sustainable development of Sri Lanka in order to provide a more fruitful, happy and healthy livelihood for the populace', focusing on exploiting the ocean resources and agricultural resources in a sustainable manner.

All these plans have identified activities in various sectors necessary for further development of the country. Meanwhile the scientific community also conducted various activities once again to identify the areas in which research activities were necessary and the problems that need solutions which can be found through research studies. Generally, the findings of these studies are communicated to the rest of the scientific community through papers published in scientific journals.

Much research studies have been conducted over time and most of the findings enrich the knowledge base of the country. While agreeing with the necessity to undertake research for finding new knowledge, particularly by the academics, it is also their responsibility to focus their research on problems faced by the country and society. It will give them an opportunity to find solutions to the country's problems related to their fields of expertise.

There are urgent problems faced by the country in various sectors - agriculture, food security, energy security, environmental issues pertaining to air, water 
and soil pollution, health, industrial development through value addition of local raw material, transport, solid waste management as well as technology transfer, all of which need immediate solutions. Finding solutions to these problems is undoubtedly within the capability of the country's science and technology community. It is the responsibility of the government to create an environment conducive for science, technology and innovation to flourish enabling the scientific researchers to contribute to the sustainable development of the country.
The scientists need to conduct research on problems affecting the country at national level, find solutions based on scientific evidence and provide the necessary advice. It is important that the decision makers including politicians realise the value of such advice and make their decisions. It is important for the decision makers to appreciate the fact that such scientific advice is given maintaining accepted ethical values. A country can achieve sustainable development only if the decision makers base their decisions purely on scientific evidence.

Nalini Ratnasiri 